\title{
Un estudio sobre movilidades e inmovilidades en la Frontera Sur de México
}

Reseña de Ráfagas y vientos de un sur global. Movilidades recientes en estadosfronterizos del sursureste de México. Luis Alfredo Arriola Vega y Enrique Coraza de los Santos (Editores). New York, Peter Lang Publishing Inc., 2018

\author{
Mónica Gatica \\ monicagracielagatica@yahoo.com.ar \\ Instituto de Investigaciones Históricas y Sociales. \\ Facultad de Humanidades y Ciencias Sociales. \\ Universidad Nacional de la Patagonia, Argentina \\ Pablo Blanco \\ pabloblanco72@yahoo.com.ar \\ Instituto de Investigaciones Históricas y Sociales. \\ Facultad de Humanidades y Ciencias Sociales. \\ Universidad Nacional de la Patagonia, Argentina
}

Cita sugerida: Gatica, M. y Blanco, P. (2021). Un estudio sobre movilidades e inmovilidades en la Frontera Sur de México [Revisión del libro Ráfagas y vientos de un sur global. Movilidades recientes en estados fronterizos del sur-sureste de México por $\mathrm{L}$. Arriola Vega y E. Coraza de los Santos (Eds.)]. Sociohistórica, 48, e150. https://doi.org/10.24215/18521606e150 
A partir del abordaje de las movilidades humanas en la frontera sur de México, la obra es un esfuerzo por reunir miradas, enfoques y temáticas que acontecen en el territorio, para ponerlas en conocimiento y a la vez gestar una memoria académica de la diversidad de enfoques con las que son analizadas.

Así, temas como los circuitos transnacionales de las violencias hacia lxs migrantes, la lucha migrante y las estrategias de supervivencia que se ponen en juego, o el concepto de inmovilidad forzada incluido dentro del tránsito, son centrales para continuar pensando las movilidades con mayores perspectivas interdisciplinarias y transdisciplinarias.

Los desplazamientos de personas tienen cada vez más implicaciones políticas: se establecen zonas de tránsito, con resignificaciones de las fronteras, lo que da cuenta de la complejidad de los procesos migratorios.

El texto aborda movilidades pensadas como procesos voluntarios y deseados, y también como forzados. Todas dan cuenta del camino dialógico entre lo local y lo global, cada vez más interrelacionado y conectado, y ponen de manifiesto la consideración de los sures diversos: desde Uruguay hasta México, pasando por Centroamérica, entre otros. Son movilidades complejas, que provocan desplazamientos de nuevo cuño, en cuya génesis se hallan la pobreza crónica, la exclusión social, el racismo, la corrupción, instituciones ineficientes, desastres socioambientales y conflictos por y en el territorio con las multinacionales. Los editores someten a discusión el concepto de violencia pensándolo en tanto fenómeno de larga duración y plantean que su uso tiene dos intenciones: no generalizar sobre la especificidad de lo que está sucediendo, y además, enfatizar las diversidades que se conjugan para comprender por qué la gente está siendo expulsada y su salida tiene la forma de huida. Es importante cómo refieren a la violencia estructural, a la violencia simbólica o cultural; a la violencia microsocial; a la violencia criminal, todas ellas derivadas de la ineficiencia de la seguridad pública.

Coraza de los Santos, en el capítulo 1, problematiza la significación geopolítica de la Frontera Sur. Revisa la encarnación de la figura del enemigo, representado por el comunista como enemigo interno, el narcotraficante y el terrorista como enemigos globales, haciendo hincapié en el predominio del paradigma "securitario". Muy significativo es cómo piensa el impacto de las políticas globales en la cotidianidad de las personas. Advierte sobre procesos y fenómenos que sobrepasan los conceptos tradicionales de frontera y límite, y sobre el incremento y el significado del tráfico de personas en tanto emergente de la irrupción en escena de un sujeto sin derechos. La movilidad representa incertidumbre, con un presente inestable, que desdibuja los límites entre las conceptualizaciones de migraciones económicas y migraciones forzadas.

En el capítulo 2, Yaatsil Guevara Gonzalez ahonda en el concepto de Inmovilidad forzada, haciendo hincapié en septiembre de 2001 para contextualizar las políticas de externalización de las fronteras y de los mecanismos de control, que convirtieron todo México en una gran frontera, y al resto de Centroamérica en territorios de militarización, control y estaciones migratorias para detención de personas. En las trayectorias migratorias, se profundiza la incertidumbre, la violación de los DDHH, y la inmovilidad forzosa.

Aunque la perspectiva de género se halla presente en toda la obra, en el capítulo 3 se muestran experiencias concretas de mujeres centroamericanas inmovilizadas en la frontera sur. Aquí, Heather Wurtz profundiza en las violencias a las que son sometidas por su condición de mujer migrante, a partir de la teorización de las emociones y de la inmovilidad. La espera en todo el proceso es una situación que tendría que vincularse estrechamente con la movilidad y atender a lo que implica sobrellevar la crisis y los peligros que deben afrontarse por el incremento de controles en las rutas más conocidas. Los cuerpos están estancados por la violencia de la inmovilidad pero, a la vez, Wurtz considera que la espera y el sacrificio son condiciones necesarias para lograr los objetivos a largo plazo.

El trabajo de Rodrigo Alonso Barraza García, en el capítulo 4, resulta de sumo interés para pensar lo transfronterizo como un continuo sociocultural desregulado, en el que los cuerpos transfronterizos se reconfiguran en constante (re)invención y resistencia. El autor señala el elemento transversal que representa la violencia en tanto mecanismo de intersubjetivación, como eje de relacionamiento social y como motor 
de experiencia cotidiana corporizada y encarnizada. Hay un tránsito de la vulnerabilidad estructural a una vulnerabilidad itinerante y pendular caracterizada de modo hegemónico para hacer de lxs migrantes "cuerpos ilegales" a partir del paradigma de "securitización”. Las personas migrantes son "un riesgo"; son cuerpos disponibles, cuerpos-máquinas, en lo que subyace una docilización. En los casos que aborda se muestra una hipersexualización de las mujeres migrantes que se convierten en cuerpos públicos, sometidos a violencias naturalizadas. Lxs migrantes son representadxs como cuerpos saturados de otredad.

En el capítulo 5, Luis Alfredo Arriola Vega reflexiona en términos metodológicos y éticos sobre el estudio de la violencia contra migrantes centroamericanos no autorizados en México, en el período 2009-2011. Al dar cuenta de la infiltración de la corporación policial, y revisar sus implicancias, pone en evidencia también el universo de actores que perpetran hechos de violencia contra los migrantes, revisando el espinoso tema del crimen organizado. Es relevante la posibilidad de comparar escenarios y territorios, pensando en la constitución, en tanto repositorio documental, de la información proporcionada por la Pastoral de la Movilidad Humana.

Suleikys Guerra Domínguez, en el capítulo 6, "Migración, cambio socioeconómico y reivindicación de guatemaltecos naturalizados en Campeche respecto de su patrimonio inmaterial", aborda la experiencia de migrantes del pueblo Mam de Guatemala en San Domingo Kesté. Aprecia la continuidad de esta movilidad en la región, desde 1980, pero en la actualidad dichos migrantes constituyen o son destinatarios de la "mexicanización forzada". Analiza las principales expresiones de la cultura y la identidad Mam que, desde la perspectiva del grupo, conforman actualmente una parte de su patrimonio inmaterial; son expresiones que se conservan a partir de su historia, del dolor y de la esperanza y la voluntad colectiva.

El libro, sin duda, se constituye en referencia para pensar múltiples abordajes y problematizaciones de una realidad que nos interpela no sólo por la actualidad del fenómeno, y la rigurosidad con la que se aborda la cuestión, sino también porque propone una original e innovadora clave para pensar un fenómeno con especificidad en Centro América y México, pero que en mucho excede a la región y que se constituye en emergente en los distintos escenarios globales. 